\title{
Cerebral vasculitis caused by Talaromyces marneffei and Aspergillus niger in a HIV-positive patient: a case report and literature review
}

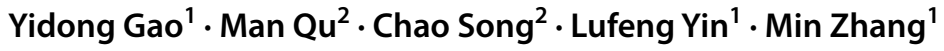 \\ Received: 6 June 2021 / Revised: 27 October 2021 / Accepted: 27 November 2021 / Published online: 3 January 2022 \\ (C) The Author(s) 2021
}

\begin{abstract}
Cerebral vasculitis is a long-standing but flourishing and fadeless research topic. Infections are a frequent cause of cerebral vasculitis, vital to diagnose due to involvement of specific anti-infection treatments. A 65-year-old man visited the hospital for his neurological symptoms without obvious inducements. After admission, radiological examination and comprehensive conventional microbiological tests (CMTs) revealed suspected intracranial infectious vasculitis. Metagenomic next-generation sequencing (mNGS) and reverse transcription-polymerase chain reaction further confirmed that his cerebral vasculitis was caused by Talaromyces marneffei (T. marneffei) and Aspergillus niger (A. niger) co-infection. The patient's final diagnosis changed from initial herpetic encephalitis, due to the past history of cephalosome and facial herpes and non-significant antiviral therapeutic effects, to fungal cerebral vasculitis. The patient was discharged after use of targeted antifungal therapies on day 18 of his admission, and his associated symptoms disappeared completely at follow-up 3 weeks later. We first illustrated the presence of uncommon cerebral vasculitis caused by T. marneffei and A. niger in a human immunodeficiency virus-positive patient. In clinically suspected patients with infectious cerebral vasculitis, mNGS should be performed to detect potential pathogens if CMTs may not provide useful pathogenic clues, highlighting the importance of mNGS in the diagnosis and treatment of infectious diseases.
\end{abstract}

Keywords Cerebral vasculitis · Talaromyces marneffei $\cdot$ Aspergillus niger · Metagenomic next generation sequencing · Human immunodeficiency virus

\section{Introduction}

Cerebral vasculitis is defined as inflammation occurring associated with destructive changes, occlusion, and infarction within the wall of intracranial blood vessels(Kraemer and Berlit 2021; Camuset et al. 2012). The prognosis of cerebral vasculitis, including infectious cerebral vasculitis, is closely related to early recognition and diagnosis due to its severity(Blancart et al. 2021; Wu et al. 2021). Thus, the key to understand infectious cerebral

Min Zhang

minzhang_2018@163.com

1 Department of Encephalopathy, The Third People's Hospital Affiliated to Fujian University of Traditional Chinese Medicine, Fujian 350122 Fuzhou, China

2 The State Key Laboratory of Translational Medicine and Innovative Drug Development, Jiangsu Simcere Diagnostics Co. Ltd., Nanjing 210042, China vasculitis is to get a good grasp of its underlying pathogens. However, conventional microbiological tests (CMTs) have competitive weaknesses, such as long turnaround time, complex process, low positive rate, and throughput. Metagenomic next-generation sequencing (mNGS), by contrast, directly detects the nucleic acid sequence of microorganisms in clinical specimens, skipping microbial culture (Gu et al. 2019; Alzahrani et al. 2021; Zhang et al. 2020), and covers a variety of pathogenic microorganisms including viruses, bacteria, fungi, and parasites quickly and objectively(Gu et al. 2019; Petersen et al. 2020). Here, we exemplified an old man who had clinically suspected viral encephalitis and was ultimately diagnosed as fungal cerebral vasculitis using mNGS. Additionally, this was the first case to report the presence of cerebral vasculitis caused by $T$. marneffei and A. niger in human immunodeficiency virus (HIV)-positive patient. 


\section{Case report}

A 65-year-old man without obvious inducements was hospitalized for slow response, decreased speech and dysphagia. Two days ago, he went to the local hospital, and his brain computed tomography (CT) examination indicated cerebral infarction with a small amount of oozing blood. To seek for further diagnosis and treatment, he was transferred to our hospital with suspected herpetic encephalitis or arteriosclerotic cerebral infarction, considering that the patient had a past history of cephalosome, facial herpes, and type- 2 diabetes. His blood pressure was 109/65 mmHg, pulse was $103 \mathrm{bpm}$, respiration was $20 \mathrm{bpm}$, and temperature was $36.8{ }^{\circ} \mathrm{C}$ on admission. Cerebrospinal fluid was obtained by lumbar puncture after admission, and then antiviral therapies (Acyclovir, $500 \mathrm{mg}$, every $8 \mathrm{~h}$ ) were given.

Laboratory examination revealed increased neutrophil percentage of $89.5 \%$ (normal 51-75), absolute neutrophil cell counts of $7.58 \times 10^{9} / \mathrm{L}$ (normal 2.0-7.0), C-reactive protein of $81.7 \mathrm{mg} / \mathrm{L}$ (normal 0-10), D-Dimer $9.42 \mu \mathrm{g} / \mathrm{mL}$ (normal 0-1), glycosylated hemoglobin of $6.20 \mathrm{mmol} / \mathrm{L}$ (normal 4-6), and erythrocyte sedimentation rate $44.0 \mathrm{~mm} / \mathrm{h}$ (normal 0-15). Meanwhile, a set of autoimmune antibody tests, including anti-U1RNP, anti-SSA, anti-Sm, anti-Slc-70, antinuclear antibody, anti-ribosomal P protein antibody, anti-SSB, and anti-J01, all indicated negative, which excluded the diagnosis of encephalitis caused by autoimmune. Other functional tests were within the normal range, except for HIV antibody positivity.

The cerebrospinal fluid cytology examination indicated that the patient's white blood cell counts $\left(15 \times 10^{6} / \mathrm{L}\right.$; normal $0-8)$, red blood cell counts $\left(480 \times 10^{6} / \mathrm{L}\right.$; normal 0$)$, total protein $(2474.0 \mathrm{mg} / \mathrm{L}$; normal $200-450)$, and lactate dehydrogenase (111.10 U/L; normal 3-40) levels significantly raised, while glucose level assay $(1.93 \mathrm{mmol} / \mathrm{L}$; normal 2.5-4.5) decreased. Cytological assay of his cerebrospinal fluid exhibited abnormal signs in the percentage of active monocytes (18\%) and plasmacytes (+) (Fig. 1a). Cerebrospinal fluid culture was negative. After admission, the brain magnetic resonance imaging (MRI) showed hemorrhagic infarction in the temporal lobe, which implied intracranial infectious vasculitis may occur (Fig. 1b). In order to confirm the diagnosis, we performed whole brain angiography on the seventh day after admission. It showed that the patient had multiple lesions in the cerebral artery, mainly in the posterior circulation. The initial part of the left vertebral artery was indistinct, the distal vessels were thin, and there was no progression far from V2. The right vertebral body was dominant, and the left posterior cerebral artery was occluded far away from P1 segment. The diagnosis of cerebral vascular inflammatory lesions was confirmed (Fig. 1c).
On day 3 of admission, the patient had thick sputum elimination with high fever $\left(38.7^{\circ} \mathrm{C}\right)$. Lung $\mathrm{CT}$ examination showed that his physical condition worsened with pulmonary infection. And the patient's sputum culture was examined, but no significantly positive pathogen culture was identified. Intravenous injection of cefotaxime sodium at a dose of $2 \mathrm{~g}$ per $12 \mathrm{~h}$ was implemented to deaden his pulmonary infections empirically. Concurrently, mNGS was performed in SimcereDx Lab (Nanjing, China) to identify potential pathogens in cerebrospinal fluid due to disease progression. mNGS revealed 13 T. marneffei and 9 Aspergillus niger specific sequences with reads coverage of $0.0044 \%$ and $0.0014 \%$, respectively (Fig. 2a, b). The following reverse transcription-polymerase chain reaction (PCR) test confirmed the pathogenic results of mNGS (Fig. 2c). Primer information of T. marneffei (101 bp): forward primer: 5-TTC CCGAGCGAGTGACAGA -3 and reverse primer 5-GCT TGTGTGTTGGGTGTGGT -3 and A. niger (500 bp): forward primer: 5-GGG CAA AGGGTTGGGTCTTC -3 and reverse primer 5' GACGAGGACGGCACGAGGA -3. Thus, his final diagnosis was adjusted to fungal intracranial vasculitis caused by T. marneffei and A. niger. And at the same time, his treatment options were changed into intravenous injection of amphotericin B from $3 \mathrm{mg}$ on day $1,5 \mathrm{mg}$ on day 2 , until $40 \mathrm{mg}$ on day 10 . In order to prevent the side effects, a small dose of dexamethasone $5 \mathrm{mg}$ was given before use.

On day 10 of admission, high fever disappeared. On day 13 , the lung $\mathrm{CT}$ examination showed significant remission of the local focus caused by pulmonary infection. The patient's symptoms improved and discharged on day 18 of admission after a long-term anti-infection. After leaving hospital, he was further treated with itraconazole $200 \mathrm{mg}$ per $12 \mathrm{~h}$. At follow-up 3 weeks later, the fever and neuronal disorders vanished completely.

\section{Discussion}

In this case, considering that the patient had a history of facial herpes and was not cured on his hospitalization, and the brain CT showed the temporal lobe lesion with hemorrhage, herpetic encephalitis was considered for prediagnosis; hence antiviral treatment was given. CMT results were negative for autoimmune encephalitis caused by HIV positivity. Genetically pathogenic analysis of $T$. marneffei and $A$. niger positive in cerebrospinal fluid excluded the possibility of herpetic infection-derived cerebral vasculitis. Meanwhile, cerebral angiography showed occlusion in the left posterior cerebral artery and hemorrhagic infarction lesions in the bilateral medial temporal lobe. Collectively, the diagnosis was finally adjusted to fungal cerebral 
A
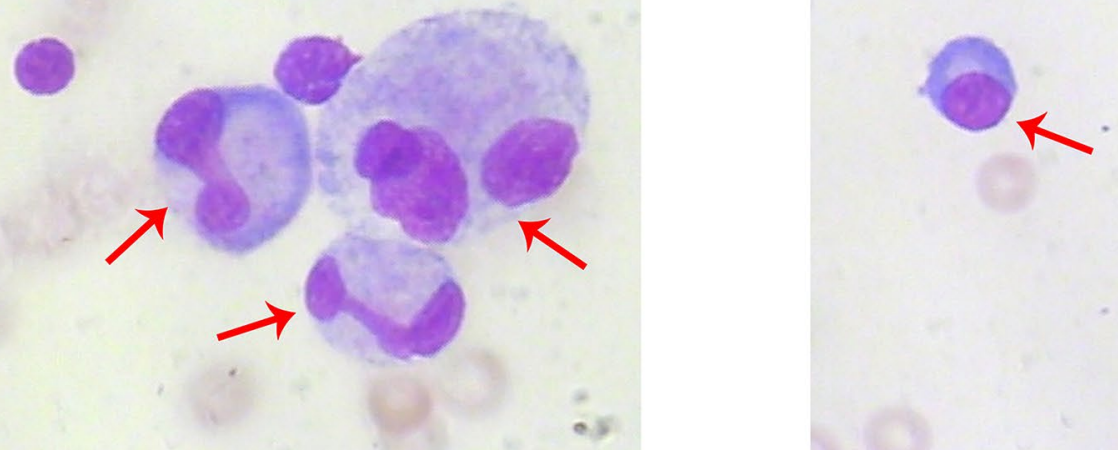

B
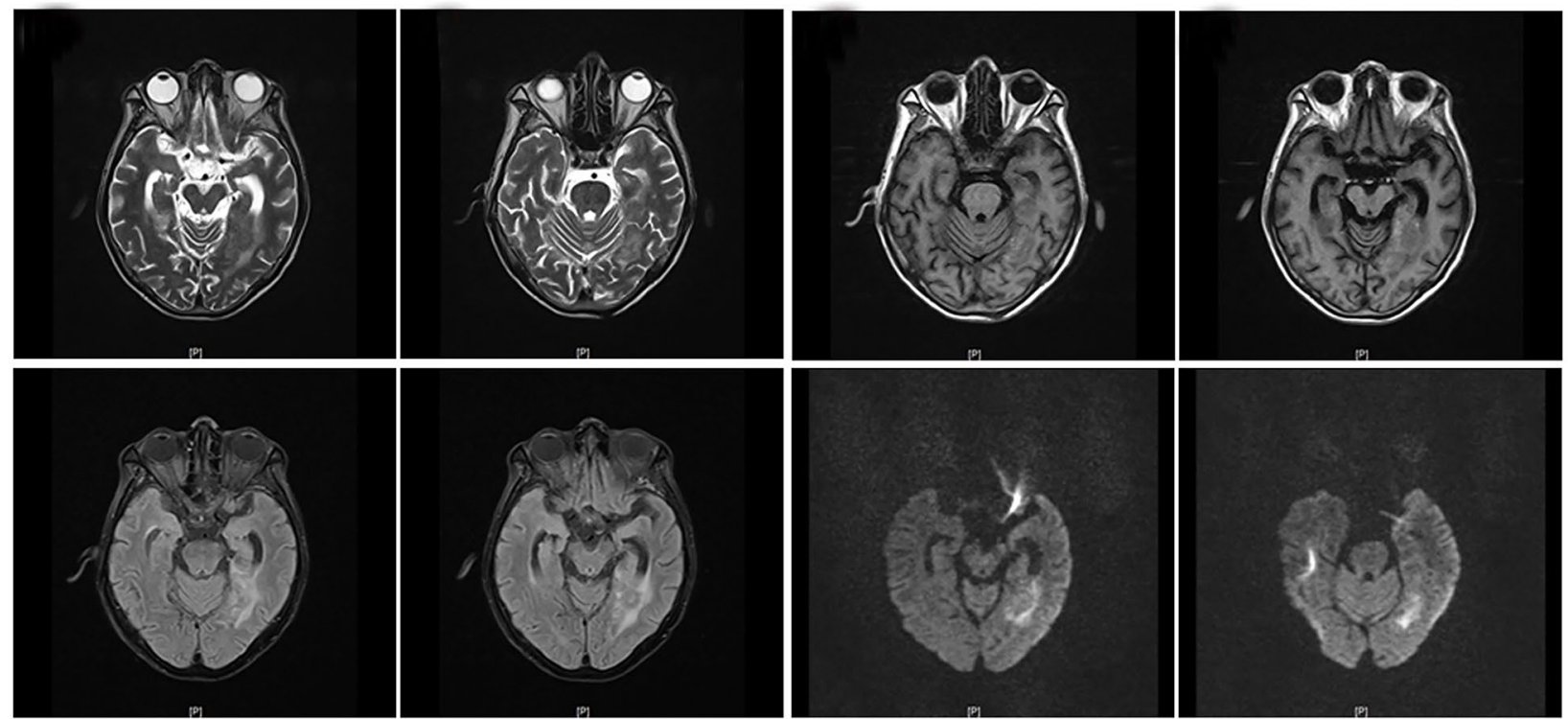

$\mathbf{C}$
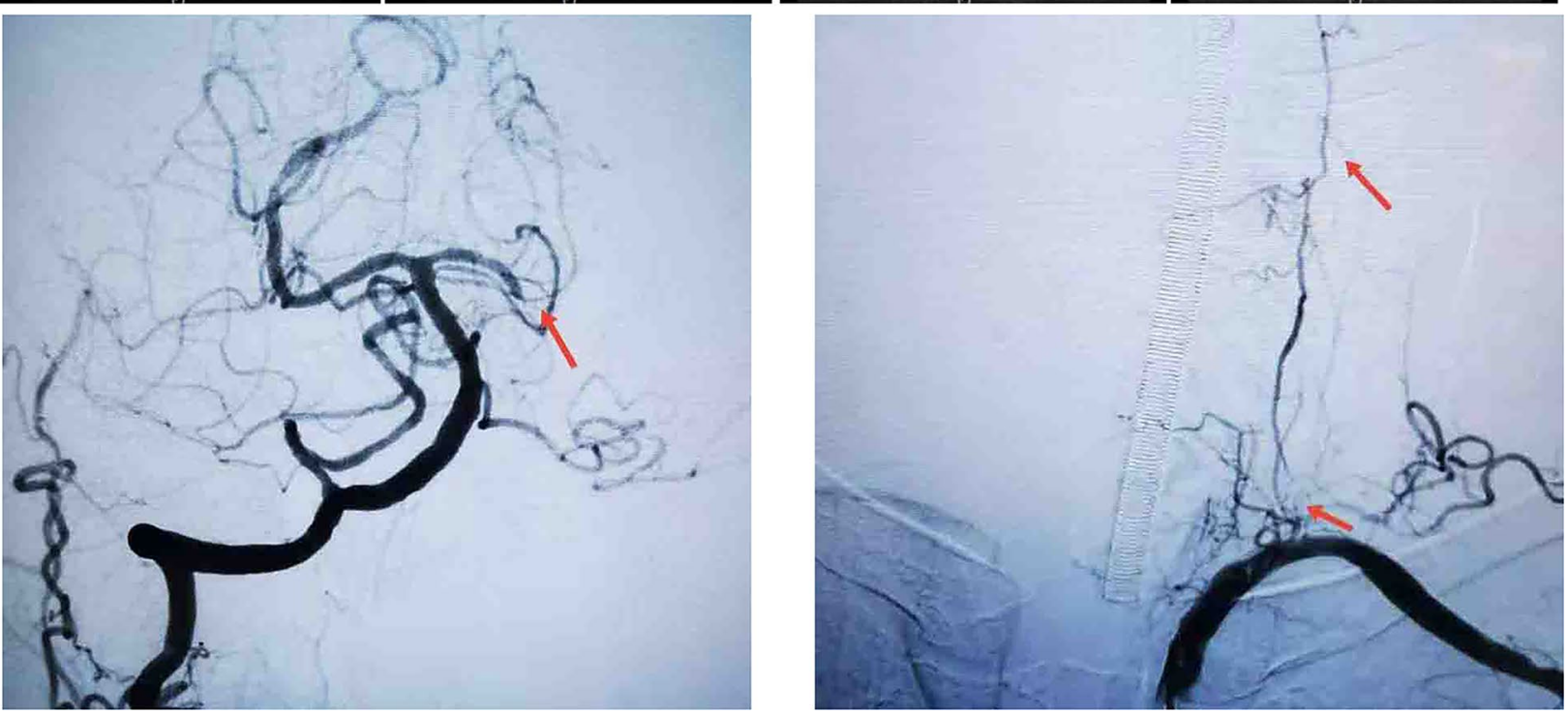

Fig. 1 Results of imaging and cerebrospinal fluid cytology examinations. (a) Image of cerebrospinal fluid cytology examination. Active monocytes and plasmacytes from left to right were indicated by the red arrow. (b) Brain MRI results. These images were in pairs from

left to right and from top to bottom, and represented T1, T2, Flaire, and dwi, respectively. (c) Cerebral angiography examination. Abnormal signals were indicated by the red arrow 

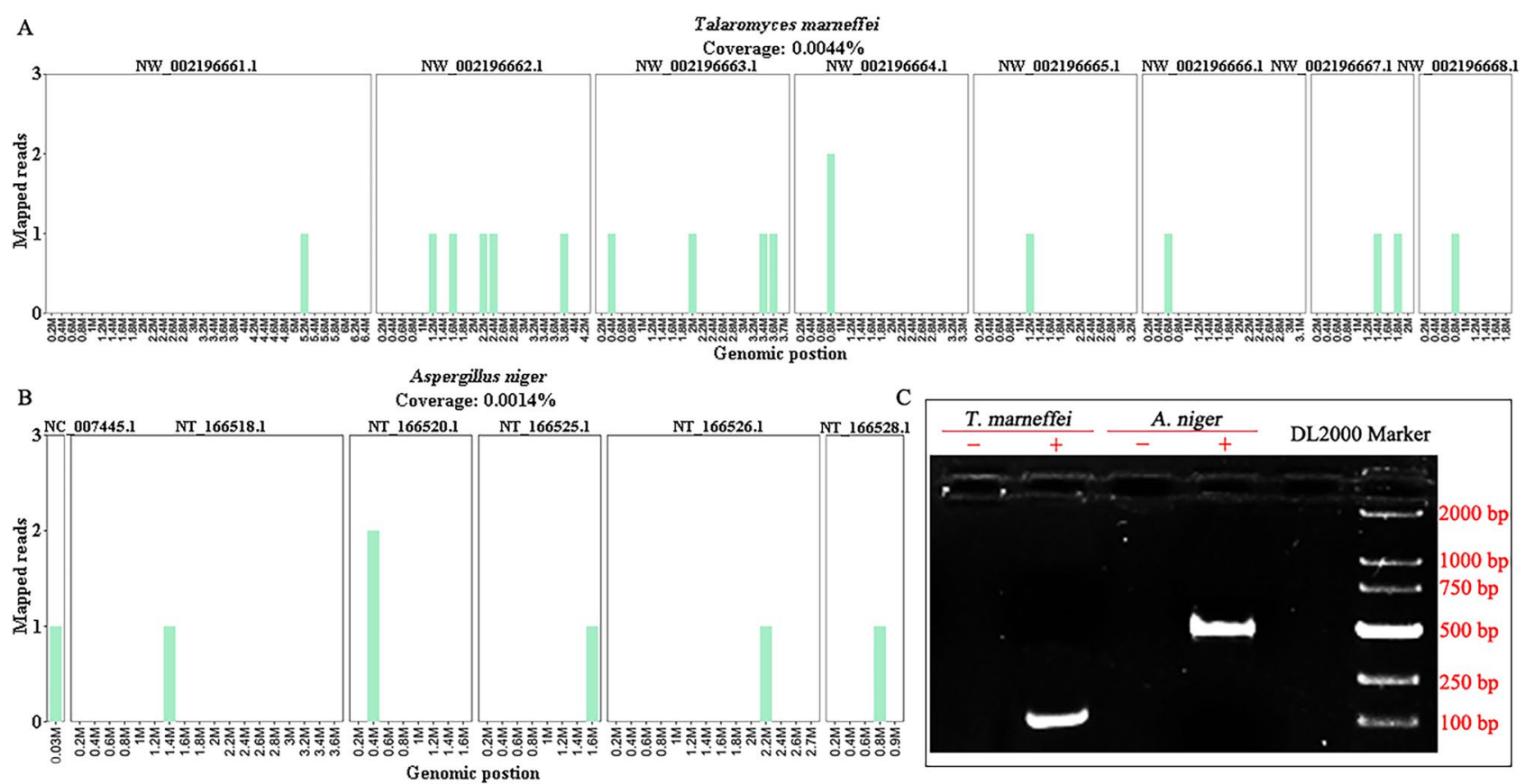

Fig. 2 Molecular diagnosis of T. marneffei and A. niger. (a) Mapped reads of T. marneffei by the means of mNGS. (b) Mapped reads of A. niger by the means of mNGS. (c) RT-PCR confirmation test

vasculitis. Apart from genetic evidence, the curative effect of targeted antifungal therapies and 3-week follow-up reaffirmed the diagnosis of fungal cerebral vasculitis.

Fungal infections are one of the major causes of adverse clinical outcomes in cerebral vasculitis worldwide (Armstrong-James et al. 2014; Gullo 2009). Since the first case of fungal cerebral vasculitis described by Rao, V.R.K. et al. a series of cases have been reported (Rao et al. 1978a). A systematic review of the fungal cerebral vasculitis was retrieved from Web of Science Core Collection, and up to May 28th, 2021, 20 papers had been published in total (Table 1). Fungal cerebral vasculitis frequently occurs in patients with severe cellular immunosuppression (hematopathy, transplantation, HIV infection, and immunosuppressive therapy), with a dismal prognosis (Jung et al. 2018; Leroy et al. 2020; Ermak et al. 2014; Eucker et al. 2000; Van Rooij et al. 2018). Infection-derived vasculitis is caused by angiogenic pathogens, including Aspergillus sp., Candida albicans, zygomycotina sp., Cryptococcus neoformans, and so on, and their etiopathogenesis can be summarized as follows: subarachnoidal meningitis, sinuses or orbital infection, and immune mechanism in the context of chronic infections (Lampros et al. 2021; Herlin et al. 2015; Thirunavukkarasu et al. 2021). Early recognition and diagnosis of cerebral vasculitis can, to a great extent, alleviate the risk of its severity and improve prognosis (Rao et al. 1978a; Jung et al. 2018; Salvarani et al. 2007; Sasaki et al. 2010; Ellis et al. 2018).

In this case, T. marneffei and A. niger were genetically verified as infectious causes of vasculitis using mNGS and RT-PRC. T. marneffei usually causes invasive fungal infection, characterized by lack of specificity in clinical presentation and difficulties in diagnosis (Chan et al. 2016). A. niger-derived invasive pulmonary aspergillosis is one of the most common mould infections in inpatients (Schmiedel and Zimmerli 2016). Both two strains primarily result in respiratory and bloodstream infections, and few cases have been described in cerebral infection, not to mention the co-infection with $T$. marneffei (Chan et al. 2016; Schmiedel and Zimmerli 2016). 
Table 1 A systematic review of the literature on fungal cerebral vasculitis

\begin{tabular}{|c|c|c|c|c|c|c|}
\hline \multirow[t]{2}{*}{ References } & \multicolumn{2}{|l|}{$\begin{array}{l}\text { Patient's } \\
\text { information }\end{array}$} & \multirow[t]{2}{*}{ Detection methods } & \multirow[t]{2}{*}{ Etiopathogenesis } & \multirow{2}{*}{$\begin{array}{l}\text { Length of stay } \\
\text { (days) }\end{array}$} & \multirow[t]{2}{*}{ Clinical outcomes } \\
\hline & Age (year) & Sex & & & & \\
\hline (Rao et al. 1978b) & 20 & - & Histological examination & Mucor sp. & - & Recovery \\
\hline (Ho and Allevato 1986) & 41 & Female & Microscopic examination & Paecilomyces javanicus & 15 & Died \\
\hline (Lee et al. 1996) & 47 & Female & Histological examination & Mucor sp. & 6 & Died \\
\hline (Grimes et al. 1998) & 37 & Female & Bacterial culture & Candida albicanss & 69 & Died \\
\hline \multirow[t]{2}{*}{ (Erly et al. 1999) } & 33 & Male & Histological examination & Coccidioides immitis & 9 & Died \\
\hline & 74 & Male & Bacterial culture & & 14 & Died \\
\hline (Eucker et al. 2000) & 18 & Female & Bacterial culture & Absidia corymbifera & 6 & Died \\
\hline (Rickert et al. 2002) & 10 & Female & Histological examination & Mucor sp. & 21 & Died \\
\hline (Roberts et al. 2004) & 71 & Female & Histological examination & Aspergillus sp. & & Died \\
\hline (Laurencikas et al. 2006) & 12 & Male & Aspergillum antigen test & Aspergillus sp. & 31 & Died \\
\hline (Marazzi et al. 2008) & 5 & Male & Histological examination & Candida albicans & 8 & Died \\
\hline \multirow[t]{3}{*}{ (Sasaki et al. 2010) } & 35 & Female & Histological examination & zygomycotina sp. & 115 & Died \\
\hline & & Female & Tissue pathology examination & & - & Recovery \\
\hline & 68 & Female & Bacterial culture & & 28 & Died \\
\hline (Martins et al. 2010) & 56 & Female & Bacterial culture & Aspergillus sp. & - & Died \\
\hline (Ermak et al. 2014) & 57 & Female & Tissue pathology examination & Mucor sp. & 2 & - \\
\hline (Moore et al. 2016) & 76 & Male & $\begin{array}{l}\text { Gomori methenamine silver } \\
\text { stain }\end{array}$ & Aspergillus sp. & 1 & Died \\
\hline (Ellis et al. 2018) & 38 & Male & Bacterial culture & Cryptococcus neoformans & 19 & Recovery \\
\hline (Jung et al. 2018) & 29 & Female & $\begin{array}{l}\text { Bacterial culture and serologic } \\
\text { testing }\end{array}$ & Aspergillus fumigatus & 31 & Recovery \\
\hline (Buchanan et al. 2019) & 26 & Male & Serologic testing & Coccidioides immitis & 31 & Partial recovery \\
\hline (Ueno et al. 2019) & 60 & Female & Histological examination & Aspergillus sp. & 48 & Died \\
\hline (Leroy et al. 2020) & 61 & - & bacterial culture and qPCR & $\begin{array}{l}\text { Aspergillus } \\
\text { fumigatus }\end{array}$ & - & Recovery \\
\hline (Polk et al. 2020) & 26 & Male & $\begin{array}{l}\text { CSF cryptococcal Ag test and } \\
\text { bacterial culture }\end{array}$ & Cryptococcus neoformans & 36 & Partial recovery \\
\hline Our study & 65 & Male & mNGS and RT-PCR & $\begin{array}{l}\text { Talaromyces marneffei } \\
\text { and Aspergillus niger }\end{array}$ & 18 & Recovery \\
\hline
\end{tabular}

\section{Conclusion}

We first reported the presence of cerebral vasculitis caused by T. marneffei and A. niger in a HIV-positive patient. By summarizing the literature on fungal cerebral vasculitis, the importance of pathogenic identification was further emphasized in the early stage. Briefly, our case highlights the crucial role of mNGS in identification of specific pathogens and provides a new insight into the diagnosis of infectious cerebral vasculitis.

Authors' contributions Conception and design, Yidong Gao, Min Zhang, and Man Qu; formal analysis, Man Qu and Chao Song; investigation, Yidong Gao and Lufeng Yin; writing (original draft preparation), Yidong Gao, Man Qu, and Min Zhang. All authors have read and agreed to the published version of the manuscript.
Data availability Data supporting the research results of this study can be obtained on request from the corresponding authors Dr. Zhang.

\section{Declarations}

Conflict of interest The authors declare no competing interests.

Open Access This article is licensed under a Creative Commons Attribution 4.0 International License, which permits use, sharing, adaptation, distribution and reproduction in any medium or format, as long as you give appropriate credit to the original author(s) and the source, provide a link to the Creative Commons licence, and indicate if changes were made. The images or other third party material in this article are included in the article's Creative Commons licence, unless indicated otherwise in a credit line to the material. If material is not included in the article's Creative Commons licence and your intended use is not permitted by statutory regulation or exceeds the permitted use, you will need to obtain permission directly from the copyright holder. To view a copy of this licence, visit http://creativecommons.org/licenses/by/4.0/.

Funding The authors did not receive funding for the current work. 


\section{References}

Alzahrani FM, Al-Amri A, Shaikh SS, Alomar AI, Acharya S, Aldossary MA, Hassan FM (2021) Direct DNA SequencingBased Analysis of Microbiota Associated with Hematological Malignancies in the Eastern Province of Saudi Arabia. Biomed Res Int

Armstrong-James D, Meintjes G, Brown GD (2014) A neglected epidemic: fungal infections in HIV/AIDS. Trends Microbiol 22:120-127

Blancart RG, Fortea G, Pérez AP, Martí S, Parkhutik V, Cruz AS, Soriano C, Sclarsky DG, Saldaña MP, Hernández NL, Beltrán I (2021) One-year prognosis of non-traumatic cortical subarachnoid haemorrhage: A prospective series of 34 patients. Neurologia 36:215-221

Buchanan IA, Ravina K, Strickland B, Fredrickson V, She R, Mathew A, Rennert R, Russin JJ (2019) Multiple intracranial aneurysms from coccidioidal meningitis: case report featuring aneurysm formation and spontaneous thrombosis with literature review. World Neurosurg 121:117-123

Camuset G, Wolff V, Marescaux C, Abou-Bacar A, Candolfi E, Lefebvre N, Christmann D, Hansmann Y (2012) Cerebral vasculitis associated with Schistosoma mansoni infection. BMC Infect Dis 12:220

Chan JF, Lau SK, Yuen KY, Woo PC (2016) Talaromyces (Penicillium) marneffei infection in non-HIV-infected patients. Emerg Microbes Infect 5:e19

Ellis JP, Kalata N, Joekes EC, Kampondeni S, Benjamin LA, Harrison TS, Lalloo DG, Heyderman RS (2018) Ischemic stroke as a complication of cryptococcal meningitis and immune reconstitution inflammatory syndrome: a case report. BMC Infect Dis 18:520

Erly WK, Labadie E, Williams PL, Lee DM, Carmody RF, Seeger JF (1999) Disseminated coccidioidomycosis complicated by vasculitis: a cause of fatal subarachnoid hemorrhage in two cases. AJNR Am J Neuroradiol 20:1605-1608

Ermak D, Kanekar S, Specht CS, Wojnar M, Lowden M (2014) Looks like a Stroke, Acts like a Stroke, but It's More than a Stroke: A Case of Cerebral Mucormycosis. J Stroke Cerebrovasc Dis 23:e403-e404

Eucker J, Sezer O, Lehmann R, Weber JR, Graf B, Denkert C, Brück W, Schweigert M, Possinger K (2000) Disseminated mucormycosis caused by Absidia corymbifera leading to cerebral vasculitis. Infection 28:246-250

Grimes DA, Lach B, Bourque PR (1998) Vasculitic basilar artery thrombosis in chronic Candida albicans meningitis. Canad J Neurolo Sci: Le J Canad Des Sci Neurolo 25:76-78

Gu W, Miller S, Chiu CY (2019) Clinical Metagenomic NextGeneration Sequencing for Pathogen Detection. Annu Rev PatholMech 14:319-338

Gullo A (2009) Invasive fungal infections. Drugs 69:65-73

Herlin LK, Hansen KS, Bodilsen J, Larsen L, Brandt C, Andersen CO, Hansen BR, Luttichau HR, Helweg-Larsen J, Wiese L, Storgaard M, Nielsen H, Mogensen TH, Encephalitis VZV, in Denmark From, (2015) to 2019-A Nationwide Prospective Cohort Study. Clin Infect Dis 72(2021):1192-1199

Ho KL, Allevato PA (1986) Hirano body in an inflammatory cell of leptomeningeal vessel infected by fungus Paecilomyces. Acta Neuropathol 71:159-162

Jung J, Jun JB, Lim DH (2018) Lim, invasive thyroid gland aspergillosis in a patient with systemic lupus erythematosus. J Korean Med Sci 33:e153

Kraemer M, Berlit P (2021) Primary central nervous system vasculitis - An update on diagnosis, differential diagnosis and treatment. J Neurol Sci 424:117422
Lampros A, Caumes E, Psimaras D, Galanaud D, Clarençon F, Peyre M, Deltour S, Bielle F, Lhote R, Haroche J, Amoura Z (2021) [Infection associated cerebral vasculitis]. Rev Med Interne 42:258-268

Laurencikas E, Sandstedt B, Söderman M (2006) Intrathecal aspergillosis and fusiform arterial aneurysms in an immunocompromised child: a clinico-pathological case report, Child's nervous system : ChNS : official journal of the International Society for. Pediatr Neurosurg 22:1497-1501

Lee BL, Holland GN, Glasgow BJ (1996) Chiasmal infarction and sudden blindness caused by mucormycosis in AIDS and diabetes mellitus. Am J Ophthalmol 122:895-896

Leroy J, Vuotto F, Le V, Cornu M, François N, Marceau L, Fichet C, Loridant S, Sendid B (2020) Invasive rhino-orbital-cerebral aspergillosis in an immunocompetent patient. J De Mycolog Medic 30:101002

Marazzi MG, Bondi E, Giannattasio A, Strozzi M, Savioli C (2008) Intracranial aneurysm associated with chronic mucocutaneous candidiasis. Eur J Pediatr 167:461-463

Martins HS, da Silva TR, Scalabrini-Neto A, Velasco IT (2010) Cerebral vasculitis caused by Aspergillus simulating ischemic stroke in an immunocompetent patient. J Emerg Med 38:597-600

Moore LA, Erstine EM, Prayson RA (2016) Pituitary aspergillus infection. J Clin Neurosci:Offi J Neurosurg Soc Austra 29:178-180

Petersen LM, Martin IW, Moschetti WE, Kershaw CM, Tsongalis GJ (2020) Third-generation sequencing in the clinical laboratory: exploring the advantages and challenges of nanopore sequencing. J Clin Microbiol 58

Polk C, Meredith J, Kuprenas A, Leonard M (2020) Cryptococcus meningitis mimicking cerebral septic emboli, a case report series demonstrating injection drug use as a risk factor for development of disseminated disease. BMC Infect Dis 20:381

Rao VR, Pillai SM, Mathews G, Radhakrishnan VV (1978a) Radhakrishnan cerebral mucormycosis - A case report. 15:291-293

Rao V, Pillai SM, Mathews G, Radhakrishnan VV (1978b) Cerebral mucormycosis-a case report. Neuroradiology 15:291-293

Rickert CH, Greiner C, Rellensmann G, Kehl HG, Scheld HH, Paulus W, Fechner G (2002) Mycotic cerebral vasculitis in a paediatric cardiac transplant patient excludes misadventure. Int J Legal Med 116:233-237

Roberts M, Carmichael A, Martin P (2004) Cerebral vasculitis caused by Aspergillus species in an immunocompetent adult. Infection 32:360-363

Salvarani C, Brown RD Jr, Calamia KT, Christianson TJ, Weigand SD, Miller DV, Giannini C, Meschia JF, Huston J 3rd, Hunder GG (2007) Primary central nervous system vasculitis: analysis of 101 patients. Ann Neurol 62:442-451

Sasaki T, Mineta M, Kobayashi K, Ando M, Obata M (2010) Zygomycotic invasion of the central nervous system. Jpn J Radiol 28:376-380

Schmiedel Y, Zimmerli S (2016) Common invasive fungal diseases: an overview of invasive candidiasis, aspergillosis, cryptococcosis, and Pneumocystis pneumonia. Swiss Med Week 146:w14281

Thirunavukkarasu B, Gupta K, Nada R, Rathi M, Dhir V, Ahuja CK, Sharma A, Lal V, Radotra BD (2021) Neuropathological spectrum in systemic lupus erythematosus: A single institute autopsy experience. J Neuroimmunol 353:577518

Ueno M, Nakano K, Yoshinari H, Nakayamada S, Iwata S, Kubo S, Miyagawa I, Tanaka Y (2019) An autopsy case with cerebral hemorrhaging due to disseminated aspergillosis during glucocorticoid therapy for overlap syndrome of systemic lupus erythematosus and systemic sclerosis. Inter Med (Tokyo, Japan) 58:1023-1027

Van Rooij JL, Rutgers DR, Spliet WG, Frijns CJ (2018) Vessel wall enhancement on MRI in the diagnosis of primary central nervous system vasculitis. Int J Stroke 13:NP24-NP27

Wu JJ, Yao M, Ni J (2021) Cerebral amyloid angiopathy-related inflammation: current status and future implications. Chin Med J (engl) 134:646-654 
Zhang HC, Zhang Y, Wu J, Li Y, Zhou X, Li X, Chen HL, Guo MQ, Chen S, Sun F, Mao RC, Qiu C, Zhu ZQ, Ai JW, Zhang WH (2020) Risks and features of secondary infections in severe and critical ill COVID19 patients. Emerg Microbes Infec 9:1958-1964
Publisher's Note Springer Nature remains neutral with regard to jurisdictional claims in published maps and institutional affiliations. 